\title{
Probing the Interface Between Learning Theory and Practice in Adult Basic Education
}

\author{
George Demetrion, Capital Community College and 1199 New England Training and \\ Upgrading Fund
}

\begin{abstract}
This essay tracks and expands upon critical exchanges with graduate students in a course for adult educators, highlighting conflicting perspectives among participants on the relative value of theory in enhancing practice. An underlying focus of the course consisted of comparing constructivist and cognitive perspectives on learning theory and their relationship to corresponding models of instructional design. To gain further insight on the theory/practice dynamic, the essay also highlights Dewey's functional theory of learning underlying his pragmatic philosophy of inquiry. Participants implicitly embraced practitioner research frames of reference, drawing out the insider perspective-a topic explicitly discussed below-as an essential counterpoint to an outsider stance, that typically orients academic research. The essay calls for critical intermingling of research traditions to facilitate collaborative approaches to problem solving in adult basic education.
\end{abstract}

Keywords: adult educators, learning theory, instructional design, John Dewey

As I read through these theoretical papers, I feel the professional academics get to dream as big as they want to, but the actual classroom teacher is the real-life practitioner who takes what might be great in theory and translates what she can into her actual working situation.

As one immersed in 37 years of classroom experience and academic discourse on the relationship between pedagogy and the political culture of adult literacy, I have experienced anxieties similar to the student, above, in my course on curriculum development for adult educators in efforts to work through pervasive theory/practice tensions. This strain has underlain my ambivalence in assigning a second week on learning theory, in a course where I wrapped around several key topics, including adult education philosophies, learning theory, and instructional design. This concern echoed those of other class members of this graduate course I designed and taught from 2009-2017 in the Virginia Commonwealth University's Online Certificate in Adult Literacy Program. Members consisted mostly of seasoned ABE, ESOL, and GED preparation teachers, many of whom worked in corrections facilities. Student reflections cited in this essay are from the 2014 and 2017 semesters. 
I highlighted several nationally prominent programs to facilitate discussion on curriculum issues. We concentrated 1 week on the CASAS Competencies (2008), which focus on consumer economics, community resources, health, employment, and government and law. We dedicated another week to the Equipped for the Future's (EFF) program with its "progressive mastery of the knowledge demands of key social roles" (Demetrion, 2005, p. 153) at home, work, and the community, processed through transferable content standards in the areas of communication, decision-making, interpersonal and life-long learning skills. We also studied the revised 2014 GED test which is based on "a thinking curriculum, teaching adults how to reason [emphasis added] in the context of real-life reading texts, science concepts, social science and writing" (GED Test Curriculum Blueprint, 2013, p. 3). This orientation represented a significant contrast to prior versions of the test centered more on mastery of a set body of knowledge in the academic content areas. Our primary textbook ( $A$ Guide for Planning and Implementing Instruction for Adults) used an integrated theme-based approach, which "places the learner's life contexts at the center of the instructional process" (Dirkx \& Prenger, 1997, p. xiii) and proved a key resource in our exploration of critical issues in adult education curriculum studies.

I included a 2-week unit on the curriculum literature, itself, which seemed to lack a sufficiently robust theoretical framework to serve as the course's intellectual center. This assessment led to my topics in curriculum studies approach, which included strong emphasis on learning theory stemming from the central role constructivism plays in shaping the direction of adult education pedagogy. I also drew on the cognitive learning literature, which provided a more structured instructional approach that many participants came to view as a valuable counterpart to the more radical strains in constructivist learning theory. We discussed many of the sources cited in this article.

Several students questioned the focus on learning theory, while others found it stimulating. One thought, "a great deal of the learning theory is hair splitting" and wondered why theorists failed to consider "the students," the alleged subject of their reflections. She noted, "each theory will include" relevance for certain students in specific contexts, but she had "yet to find a theory [that applies to] all the people all of the time." Another expressed a similar perception that no singular learning theory depicted the full range of relevant learning in all contexts; she, nonetheless, explored the topic for what it opened up of better grasping the learning process of her students. This also contributed to a deeper understanding of her self-learning. In sum, she started "asking questions about these theories and how all of this theory fits into my world." This encouraged her to think more intentionally about what "learning looks like." Others expressed similar thoughts, while shifting their perceptions throughout the semester on the relative value of theoretical knowledge in light of other areas that merited close attention. Recapped by one student, " $t]$ he theories learned were important, but it might be helpful" to infuse their insights throughout the topics we studied.

I shared some of these concerns. However, I did not want to shortchange the significance of the key differences among the learning theories, which bring out distinctive aspects of learning through the particular lens that each of them illuminates. I decided, therefore, to grapple with the discomfort while now considering, as the previously cited student recommended, more critically gauging the 
relationship between learning theory and practice throughout the topics explored should another opportunity to teach this course arise.

Students raised provocative issues on what they took as persistent incongruities between theoretical depictions-primarily of constructivism and cognitivism-and practical application. Most participants opted for a selfevident eclecticism; nonetheless, some leaned toward one theory or another, while doubting that any intellectual construct contains sufficient complexity to adequately account for the many variables that factor into the dynamic and range of learning experienced by their students.

In characterizing this ambivalence, one participant "concentrate[d] on cognitivism for a very pragmatic reason. I thought that shaping my project around the theory I most passionately believe in-constructivism-would not allow me to develop a project that could actually be implemented." In her search for "practical application," cognitive modes of instruction, "grounded in a more organized and systematic manner of building on existing knowledge ... help[s] [students] grasp and make sense of new learning." Viewed as a kind of "scaffolding," "cognitive theory" provides an essential bridge "toward the ultimate goal of self-directed learning." Rather than "compromis[ising]" her "constructivist approach to teaching," such reinforcement thickened it by connecting the need for structure through direct instruction to metacognitive learning. For any future redesigns of the course, insights such as those identified above have provoked me to consider moving toward a more interactive dynamic between learning theory, instructional design, and participatory engagement within a more integrated focus on curriculum studies.

\section{Adult Learning Theory: An Overview}

Focusing primarily on constructivist and cognitive approaches to learning, I incorporated a wide body of work on adult education principles, practice, and theory, throughout the course, that broadly draws on these perspectives. For example, the impetus of humanistic psychology, which accentuates the individualistic thread within constructivism, underlies the adult education theory of “andragogy" (Elias \& Merriam, 2005; Henschke, 2016; Knowles et al., 1998), while what Brookfield (2004) and others refer to as a more "critical constructivism" (Kincheloe, 2008), is rooted in dialectical social discourse. We explored these tensions within constructivism through critical interpretations of andragogy and self-directed learning in the second week through Brookfield's (1995) essay, "Adult Learning: An Overview" and supplemental articles by Merriam (2001, 2017), which place these concepts in more favorable light while maintaining a critical perspective.

The cognitive emphasis on informational processing informs Sticht's (1997) two-fold model linking "the mental processes that people use to acquire knowledge...to the knowledge that has been acquired using these mental processes" (p. 38). Rooted in his functional context theory (FCT), such information is typically grounded in widely recognized bodies of knowledge in the academic disciplines and practical realms. What the mind internalizes as an informational processor depends on how much knowledge the individual has assimilated in any given domain, the more of what is relevant, the better. Merrill (2002) embodies this perspective in his essay, "First Principles of Instruction," which we studied, along with Sticht's work.

In sum, the constructivist pole within learning theory is linked to the inherently subjective notion commonly identified as meaning making- 
an "emergent, developmental, nonobjective" concept rooted in "self-regulatory process(es)" that mediates the space "between existing personal models of the world and discrepant new representatives and models of reality" through "culturally developed tools and symbols" (Fosnot, 2005, p. ix). Fosnot and Perry (2005) offer additional insight on constructivism by drawing on Piaget's concepts of "accommodation, assimilation," and the formation of new "equilibrations" to explain the progressive resolutions of these tensive modes of learning through "internalizing, self-organizing behavior" (p. 20) worked out through new frames of thought within ever-expanding experiential horizons. The educational payload emerges from "cooperative social activities, discourse, and debate" within the framework of particular "communities of practice" (Fosnot, 2005, p. ix), leading to further knowledge expansion among individuals and groups of inquiring learners.

Those on the more "extreme" edges of constructivist learning theory draw a sharp line between such self-regulatory approaches and more traditional ways of learning based on "objectivism" (Cunningham, 1992). Whether the contrast is with cognitivist or behaviorist methods of learning, the critique centers on the "transmission" theory of knowledge acquisition "that learners can incorporate exact copies of teachers' understanding for their own use, that whole concepts can be broken into discrete subskills, and that context can be taught out of context" (Fosnot, 2005, p. ix).

Emerging as an outgrowth of behaviorism (Tennyson, 2005), learning theorists and instructional designers rooted in the "cognitive revolution," insist this depiction of "objectivism" is a caricature. Merrill (1992) refers to a second wave of instructional design $\left(\mathrm{ID}_{2}\right)$, which incorporates many facets of "moderate constructivism" ( $p$. 113) through models of instruction that build on existing student knowledge and foster dynamic student engagement throughout the learning cycle (Merrill, 2002). In line with constructivists, Merrill (1992) accepts the validity of "mental models," which are "modified with every new experience," while rejecting claims that there is "no shared reality" "completely idiosyncratic to each individual” (p. 103).

In agreement with Merrill, Sticht (1997) notes that efficacious instruction needs to sharpen the focus on enabling learners to master commonly established tasks and content in the various practical spheres that absorb their attention. In his early work, Sticht applied his FCT model to military-based and workplace contexts. His more recent studies range widely across the knowledge domains, as identified in the major national adult education programs and initiatives, from the 1975 Adult Performance Level life-skill categories to various $21^{\text {st }}$ century initiatives of the current period. In his numerous engagements with major policy initiatives spanning over a 50 -year career, his functional orientation has remained constant. Namely, as learners internalize well-established content in the spheres of health, civics, parenting, employment, and financial management, they also expand their basic reading, writing, and computational skills, which are usefully taught in context.

Behaviorist- and cognitivist-oriented learning theorists accept the importance of mastering information gleaned from the external environment based on recognized bodies of knowledge in the academic disciplines and the practical realms. The primary difference is that cognitivists visualize students as active learners whose mental framework is central to the potential 
mastery of such learning while rejecting rigid transmission models. In contrast, behaviorists assume an associational psychology dependent on the strength and persistence of a stimulus/ response dynamic, based, in its simplest form, on an automatic "drill and practice" (Mayer, 1996, p. 152) model resembling a more objectivist epistemology, without the need, in principle, for cognitive processing. In stressing information processing and schema development, "[c]ognitive theories focus on the conceptualization of students' learning processes and address.... how information is received, organized, stored, and retrieved by the mind" (Ertmer \& Newby, 2013, p. 51).

In linking certain strands of cognitive and constructivist learning theory in her instructional design model, Derry (1996) points to schema theory as an integrative concept through frames of reference that individuals build in the process of assimilating new spheres of knowledge in given areas of focus. These can be simplistic, in which expanded learning is limited, or "higher order" (p. 167), enabling learners to incorporate new knowledge within a given domain, resulting in more comprehensive mental frameworks.

Mayer (1996) builds on a similar quest in identifying earlier and later work on informational processing models of assimilating knowledge. The former, which he refers to as a "literal" mode, is based on a linear, mechanistic understanding of "mental representations" (that of simply picking up discrete pieces of information). Against this, he posits a more sophisticated model, based on "memory representations" visualized in terms of broader acquisition in which "knowledge can be schematic" (Mayer, 1996, p. 156). In the shift from earlier to later models of information processing, there is more of an emphasis on "active search[ing] for understanding in which incoming experience is reorganized and integrated within existing knowledge" (Mayer, 1996, p. 156).

Derry (1996) and Mayer (1996) blend some of the more sophisticated aspects of cognitive learning theory with its linkage to constructivist approaches, which offer intriguing potential for instructional designers and educational practitioners to draw widely in shaping curricula, syllabi, and instructional methodology. As similarly argued by Çeliköz et al. (2016), such convergences between cognitive and constructivist models of learning make a radical separation between them "impossible" (p. 42). Nonetheless, there is reason for constraint in any too-ready embrace, as their primary metaphors point in different directions. While the more recent work in cognitive learning theory shares with constructivism an emphasis on dynamic, active learning, it is still beholden to a model of mind in which learners take in given information from the external environment based on the efficacy of memory retrieval. The difference between this orientation and that of reconstructing knowledge from more meaning-making, social, cultural, and self-regulatory frames of reference is significant in identifying what is most critical to learning and in corresponding modes of instruction. How practitioners and theorists grapple with this tension in ideal theory construction in light of important commonalities at the level of instructional implementation will likely shape some of the more important research in adult learning in the coming years.

\section{Scholarly and Applied Theory/Research Distinctions}

The commonly perceived tension within the theory/practice relationship in education is broadly akin to that between the academic 
researcher and medical practitioner. Unlike the research scientist, who typically seeks to resolve theoretical sets of problems, the health professional draws on formal medical research to deal with more practical types of problems, such as what drug (if any) and dose to prescribe to a given patient. Based on this pragmatic impetus, "it is making the sick man better or worse ... which determines the knowledge value of certain findings of fact and certain conceptions as to modes of treatment" (Dewey, 1916/1954, p. 21). Stated otherwise, the interactive relevance of the data, as sifted through various suggested explanations (working ideas) of causation or influence, is discovered in resolving, meliorating, or gaining a better understanding of the issues involved in contending with the immediate problem at hand.

Such field-based aptitude is further honed through comparative analysis of critical cases through discussions with colleagues, special seminars, and keenly scrutinizing medical journals for relevant information. The specialist keeps attuned to research pertinent to his or her specialty and draws on it to assess some practitioner-based issue rather than to resolve theoretical ones, as such, in which "ideas... are anticipations of possible solutions." Based on this instrumental logic, ideas function "to guide and organize further observations, recollections, and experiments" (Dewey, 1916/1944, p. 160) in working out, in this case, a viable diagnosis to a medical problem.

Classroom instructors have valid reasons for focusing on direct application, given the selfevident assumption that unless its insights lead to enhanced practice, it is difficult for most teachers to conclude what formal scholarly insight offers them. This critical discernment is underplayed in the scholarly literature which practitioner researchers seek to rectify. Notwithstanding this piercing critique, academic scholarship_ideally, in dialogue with critical practice-can open up frames of reference by which to structure learning activities through its explicit directional focus that otherwise might "not even have been noticed" (Dewey, 1929/1958, p. 5), even in the most critical common-sense reflection lacking formal theoretical input.

Sifting through these tensions calls for much acumen. In the course under discussion, students probed the learning theory literature with particular attention to its diverse applications to their unique classroom contexts. Underlying this complexity, one student typified a widely shared view that "in practice, the best approach is to draw on whatever theory/strategy works best in a given situation." In making such judgments, how one envisions the learning situation is a critical matter, in which the practitioner researcher or academic scholar, alone, is likely to possess only partial insight. The ideal, then, is for mutual inquiry, in which "practitioners" participate as "knowledge generators, as collaborators with university-based and other researchers in exploring practice-based issues" (Cochran-Smith \& Lytle, 2009, p. 160).

Tennyson (2005) offers a bridge by highlighting the centrality of instructional design. In his call for "an interactive network of metatheories," he contends that "[i]nstructional designers... will increasingly choose to apply a particular learning and/or instructional theory only to those narrow learning outcomes which it works most effectively." Such judgment requires addressing various "skill[s]" and "subskill[s]" needed in mastering the wide range of processes, problems, and topics students confront within the various learning environments they engage. This includes "alter[ing] each of the original [learning] models used" (Tennyson, 2005, p. 233) based on rigorous analysis of needed micro-skills, along with the 
metacognitive resources required to enhance the capacity of students to think and act in integrative ways in working through any complex matter.

While emphasizing the pragmatic impetus of efficacious learning, Tennyson (2005) calls for educators to grapple "with the lack of a means of defining a philosophy and learning theory by which instructional design methodology can be driven" (p. 234). That bow to theory, notwithstanding, the extent to which to place primary emphasis on learning theory rather than instructional design in any given context, remains a critical matter requiring much discernment among the various stakeholders. This is so because the very definition of what counts as significant in any specific situation is a matter of contestation among participants in determining the extent to which a paradigmatic (typically more theoretical) shift in learning or a more incremental design issue is most desired.

\section{The Deweyan Contribution}

Whether formally identified as such, dependence upon theory as a directive force guiding any investigation is an essential task of the classroom teacher. Advocates of practitioner research contend, field-wide transformation is a distinct possibility when it becomes a matter of course for instructors to initiate theory construction from their own frames of reference (Cochran-Smith \& Lytle, 1993, 2009). A closely related sensibility is that of teachers contributing to current scholarship on learning and instructional theory by drawing on their own classroom experience in raising critical issues and identifying their own points of reference. Most seminar students responded to these challenges by drawing out facets of learning theory germane to their own classroom contexts.
Some referred to Knowles' work on self-directed learning and accompanying philosophy of education identified as andragogy (Henschke, 2016; Merriam, 2017). Sharing a close affinity with this instructional model, various participants identified constructivism as central to adult education practice while recognizing that in certain taskbased contexts, cognitive and behaviorist emphases gain increased saliency. Several found a new theoretical taproot in their own discovery of the "cognitive revolution" in education.

In assigning readings from Democracy and Education, I brought to the fore Dewey's (1916/1944) concept of "growth," as the "cumulative movement of action toward a later result" (p. 41), an imaginative frame of reference through which I have sought to build a "middleground" adult literacy practice (Demetrion, 2002). Dewey $(1916 / 1944)$ premises such growth on the plasticity of human nature underlying the efficacy of human power and potentiality enacted in the midst of change. This "ability to develop" (Dewey, $1916 / 1944$, p. 42) unleashes the potentially of learning as a creative force. It is

$$
\begin{aligned}
& \text { the power to retain from one experience something which } \\
& \text { is of avail in coping with the difficulties of a later situation. } \\
& \text { This means the power to modify actions on the basis of the } \\
& \text { result of prior experiences, the power to develop dispositions } \\
& \text { [original italics]. Without it, the acquisition of [a fruitful set of } \\
& \text { educational] habits is impossible. (Dewey, 1916/1944, p. 44) }
\end{aligned}
$$

In sum, Dewey's growth-focused pedagogy is rooted in a naturalistic type of inquiry that mediates the gap between a pressing problem of some existential significance and its proximate resolution, in which ideas, as increasingly refined suggestions, interact with the relevant facts of the matter to modulate the problem situation throughout the investigative process (Burke, 1994).

Consider an adult learner returning to class after an unsatisfactory job interview. The student 
carefully reviews what worked well and what re-adjustments are required for better results, including determining whether the problem lies in some needed interpersonal competency, additional job-specific skills, or another career focus. With a plausible diagnostic as a guiding framework (a working theory), the student is better situated to re-assesses a given position and better poised to develop whatever soft or hard skills require additional attention. In the case at hand, the student has obtained a more nuanced understanding of the needed skill sets in light of the range of jobs for possible consideration, along with, perhaps, an enhanced set of presentation skills designed for better job interview performances. This student "acquires a [better] habit of learning. He learns to learn" (Dewey, 1916/1944, p. 45).

Throughout the past century, educational philosophers have drawn on Dewey's work (Cherryholmes, 1999; Garrison, 1997; Gert et al., 2004), which has much untapped potential in enhancing adult education theory and practice (Stewart, 1987). While largely absent in the contemporary learning theory literature, Dewey established a sophisticated form of inquiry in philosophical pragmatism in the searching quest for progressively resolving problems through the rigorous process of establishing more viable learning and social environments, whether in formal schooling or in the broader socio-cultural realm.

Over the past few decades, a major revival of philosophical pragmatism has emerged in the professional literature, initiated by Rorty's (1979) Philosophy and the Mirror of Nature. Extending beyond education in its narrower definition, the movement includes contemporary pragmatic studies in the realms of art, politics, religion, ethics, metaphysics, and inquiry (Cochran, 2010). I have sought to raise the significance of Dewey's philosophy for the field of adult literacy studies, including practitioner research (Demetrion, 2000, 2002, 2012). With these factors circulating in my mind, I chose to incorporate the pragmatic perspective into the course work, which added an important, yet somewhat neglected dimension to the more widely recognized focus on constructivist and cognitive frames of reference.

\section{Theory/Practice Nexus}

Notwithstanding significant convergences, each of the theories highlights different aspects of learning and implications for teaching. Cognitivism, constructivism, and pragmatism function as hypothetical constructs empowered by their overarching metaphors: informational processing, meaning making, and Dewey's Darwinian model of growth through progressive problem solving. The argument put forth here is not that learning theory drives the focal point of learning. That grounding orientation belongs to the search for adequate resolution of problems that emerge from the interaction between the relevant facts and provisional ideas, as suggestions and increasingly refined inferences in any given context (Dewey, 1916/1954, 1938/1991). Thus, regardless of how the theory/practice dynamic gets worked out in any given context, the driving force in an investigatory process remains the resolution of a given learning problem, in which theory, as an orienting idea, functions as an indispensable guide. The following discussion is intended with this understanding in mind.

Insights gleaned from constructivist learning theory are useful in encouraging students to expand their thinking when the topic draws out the sensibility of empathy in strengthening bonds among learning communities, or for critical probes into different points of view that rely, to a significant degree, on self-reflection. Critical 
probing of alternative perspectives in the analysis of fiction, historical interpretation, contemporary social issues, and personal narrative reflection depends extensively on acute constructivist sensibilities, though other modes of learning also come into play.

Instructional strategies that draw from cognitive approaches can help students progressively master a series of tasks about new work processes, starting a business, or mastering the fundamentals of algebra. While a nearer-term, skill-based knowledge acquisition focus may necessitate well laid-out learning sequences, longer-term development requires subtler internalization of a range of tasks and objectives, in which one's identity as a competent knowledge user becomes positively reconstructed as part of the ongoing process of applied learning in real-world contexts. Thusly viewed, cognitive learning principles merge into constructivist ways of knowing, as Merrill $(1992,2002)$ and Sticht (1997) exemplify, even as both veer toward a "common sense" cognitive orientation in their emphasis on integrated skill-based mastery through "moderate" incorporation of constructivist propensities into an “informational processing" model of learning.

While superseded in many ways, behaviorist theory opens the importance of automaticity in facilitating phonemic awareness or in mastering the fundamentals of basic arithmetic, where practice through engaged repetition is one of the critical skills that can lead to independent learning. These activities are typically enhanced by a cognitive sensibility that helps students internalize schematic frameworks needed for long-term memory processing (Çeliköz et al., 2016). Such efforts logically lead to competent selfperception that serves an invaluable, legitimizing role enhancing learner persistence when challenges are difficult, yet potentially in reach for student realization (Bandura, 1994).

Pragmatic modes of learning support learning encounters emerging out of some deprivation in felt experience-such as unexpected job loss-in the pivotal challenge of progressively overcoming the gap through forms of knowledge that lead toward attaining a more desirable end. Competent problem solving, as determined by engaged participants, orients the fundamental purposes of a pragmatic-focused mode of inquiry (Demetrion, 2012; Dewey, 1938/1991). Constructivist

predispositions reinforce this pragmatic impetus by bolstering intrinsic motivation, which in turn can strengthen commitment to the sequential mastery needed for some complex set of tasks required to meet the challenges of coping effectively with a new learning challenge.

There is much to consider in grappling with learning theories, such as the emphasis on constructivism in current adult education theory, as well as confronting the various contexts where its utilization may be limited or counterproductive. On the latter, Merrill's $(2002,1992)$ work on principles of instruction and second level instructional design and its correspondence to Sticht's (1997) FCT model, argue for well thought out sequenced learning modules for attaining proficiency in a wide array of practically-oriented realms. In sifting through Merrill's ID ${ }_{2}$ perspective and Sticht's FCT model, course members gained a better sense of the differences and similarities between moderately constructive, cognitive perspectives and that of the main textbook's (Dirkx \& Prenger, 1997) more radical constructivist-oriented, themebased perspective. A fundamental dividing point does not center on the value of theme-based instruction, nor on the importance of knowledge internalization, which Merrill and Sticht fully 
share with Dirkx and Prenger. A primary difference is the ways that learning and supportive teaching take place between Dirkx and Prenger's model, in which direction emerges organically from goals and themes identified by students, and Merrill and Sticht's top-down instructional preplanning approach based on the expert knowledge of the teacher and instructional designer.

On the matter of who sets the selection of topics and teaching methods, Dewey (1938/1997) rejects either/or approaches. On his argument, the teacher vigorously participates as a full classroom partner based on interpersonal competence, teaching facility, and subject matter knowledge, while simultaneously encouraging direction to emerge from the background, talents, and knowledge base of the students. For Dewey, it is less about who provides initial guidance than that the learning community moves from any current knowledge base toward progressive realizations of mutually identified outcomes in a manner that facilitates optimal learning.

\section{Concluding Remarks}

A concerted effort has emerged in recent decades to establish creative dialogue between learning theorists and instructional designers, beginning, in force, with our course's second major text, Constructivism and the Technology of Instruction (Duffy \& Jonassan, 1992). In this pioneering work, the editors sought to overcome the enduring gap between the two fields stemming from "a general lack of familiarity with each other's work" and "even lack of interest in the work of the other" (p. ix). In its range of theoretical explorations and practical applications, this text is wide-ranging in opening up critical dialogue between learning theorists and instructional designers. Its more descriptive chapters provide various concrete examples on the ways in which constructivist and cognitive modes of instructional design can be intricately interwoven (Duffy \& Jonassan, 1992), with which course members most resonated, while those chapters primarily focused on theoretical issues put greater stress on the significance of the philosophical differences of divergent learning theories. Students engaged this text with much discernment as they worked though the numerous insights of the contributors in light of their own varied teaching challenges. However, this landmark study only partially overcame the persisting tension between the commitment to an unalloyed constructivism, held by most of the learning theorist contributors, and persistent behaviorist and cognitivist models that continue to exert strong purchase in the operative assumptions of the instructional design authors (Duffy \& Jonassan, 1992). This was somewhat mitigated through various distinctions between "moderate" and "extreme" perspectives underlying the constructivist vision and the willingness of the invited instructional designers to draw in aspects of moderate constructivism while remaining anchored to an implicit cognitive learning theory.

The dialogue continues. Mayer (1999) proposes an approach to teaching based on "well designed direct instruction" (p. 143) rooted in informational processing and retrieval modes of learning. Specifically, he offers a model of reading instruction designed to stimulate "working memory" (Mayer, 1999, p. 148). Buttressed by text-based, study-skill prompts such as "advanced organizers, illustrations, worked out examples, and elaborative questions" (Mayer, 1999, p. 155), the instructor assists students in building up their working memory as an essential baseline to enhance their meaning making aptitude at higher levels of potential applicability. Such scaffolding enables students to "identify useful information, to understand how the material fits together, and 
to see how the material relates to prior knowledge" for "selecting, organizing, and integrating" (Mayer, 1999, p. 152) what is important in any given learning setting.

He maintains that directive learning processes substantially enhance students' learning and knowledge-based development needed to effectively grapple with content that transcends mastery of the specific skills or knowledge attained. In this, Mayer (2004) provides a mediating pedagogy from the side of instructional design in arguing that "a dispassionate review of the relevant research... shows that discoverybased practice is not as effective as guided discovery" (p.18).

Hmelo-Silver et al. (2007) offer a similar convergence from the side of constructivist learning theory. Specifically, the authors challenge the contention by cognitive load theorists that pedagogical models founded in constructivism and "minimally guided instruction" (HmeloSilver at al., 2007, p. 99), downplay more directed instruction needed to enable learners to effectively manage informational flow. Kirschner et al., (2006) hone their critique by claiming that discovery-based models of learning, such as Problem-Based Learning (PBL) and Inquiry Learning (IL) limit minimal guidance. HmeloSilver et al. (2007) argue that PBL and IL modes of learning do incorporate the necessary scaffolding to bridge the gap between what students currently understand and what they need to know to master the learning challenges these approaches open up. In thus arguing, the authors seek to include critical features of cognitive load theory within an overarching constructivist model by utilizing certain aspects of direct support, such as straightforward "justin-time" instruction, "once students experience a need to know the information presented" (Hmlo-
Silver et al., 2007, p. 100).

One seminar student noted that the Kirshner et al. (2006) essay caused her to question constructivism while, in her words, agreeing with Hmelo-Silver et al. (2007), "that there are ways to infuse constructivism into the curriculum" that nonetheless challenges the latter's emphasis on "just in time" instruction. Specifically,

What are we teaching? Is it background knowledge that the students need in order to complete the project or one aspect of the project? Is it new information that was not given? Is it steps in the project that may not have been clearly laid out, that the teacher is then going back to correct?... It felt to me that, Kirschner et al. were not negating the fact that PBL and IL are not scaffolded, but that they put too much strain on the working memory of students. If students are working through the project but need information that they have not been taught, they must remember the process of the project and this new information. If the process of the project is something that is being repeated at various intervals of the semester, students will eventually recall the process of problem solving, but if important information is only given to them in just the right moment, will they remember that information when they'll need to eventually recall it?

In short, this student called for a robust approach to learning through modes of internalization reflective of constructivism and metacognitive learning strategies while maintaining the central cognitive emphasis on memory enhancement to facilitate long-term knowledge development.

Hmelo-Silver et al. (2007) also referenced the challenges of educating "lifelong learners and citizens in a knowledge society." Applying the complexity of this ambition to the many constituencies invested in contemporary models of education, the authors called for "deeper and more detailed understandings of the interrelationships between various instructional approaches and their impact on learning outcomes in different contexts" (Hmelo-Silver et al., 2007, p. 105). 
This cautionary note extends to the broad tent of adult education. Given the range of constituents served-from low-level literate adults of all ages, to those preparing for high school completion, transition to college, and worker preparation programs - no single learning model, no overarching curriculum, will uniformly apply. While, perhaps appealing, no all-encompassing mode of preparing workers and citizens for the $21^{\text {st }}$ century will do.

Models abound within the U.S. adult education sector: the National Institute for Literacy's founded Equipped for the Future (EFF) Project and the Partnership for $21^{\text {st }}$ Century Learning (P21 Framework Definitions, 2009) provide among the broader initiatives in linking critical knowledge development in basic and core academic skill mastery with thoughtfully engaging the informational challenges of a postindustrial and global economy, society, and culture. Critical thinking, communications, career planning and the development of interpersonal competency, stream across both programs, along with mastery of information and communications technology and the metacognitive aptitude for knowledge transference across learning domains. Disciplines range from global, health, environmental awareness, and financial and business literacy (P21) to worker-based, civics, and family education (EFF). Both frameworks are intended to prepare students for meeting the learning challenges of thriving in the $21^{\text {st }}$ Century.

\section{The Common Core State Standards (CCSS)} provide the underpinning for the College and Career Readiness Standards for Adult Education (CCR) and the revised 2014 GED test. These programs focus on academic development in the language arts, social studies, biological and physical sciences, and mathematics through selective content mastery and critical reasoning skills that provide the baseline knowledge competence to meet the "the rigors of postsecondary training, work, or citizenship" (Pimental, 2013, p. 1).

The CCR project author identifies "complexity of text" mastery as "the greatest predictor of success in college and careers" (p. 9), requiring programs to exponentially raise the content level of reading material in current use. To prepare students, teachers need to build in "academic vocabulary" and incorporate content and approaches to learning that cut "across the disciplines of science, history, and the arts" (p. 9) with an increase focus on "content-rich informational non-fiction" sources (p. 10). The revised 2014 GED test parallels these emphases while providing pinpointed content and attentiveness to key intellectual practices in each of the subjects, and two major focusing themes in the social studies and sciences (GED Test Curriculum Blueprint, 2013). These challenges call on learners to draw on an array of learning styles, approaches, and sensibilities that no singular learning theory or instructional design can provide. Rather, such proficiency requires considerable concentration, which builds on memory and informational processing activities, integrative schematic restructuring, knowledge expansion, and problemsolving aptitude.

Convergence between learning theorists and instructional designers get at some of the contemporary complexities of the knowledge building challenges adult learner communities confront. A critical missing piece remains-the insights of the classroom teacher that CochranSmith and Lytle $(1993,2009)$ bring to the fore through the underappreciated field of practitioner research. As they note, "the insider status of the [practitioner] researcher is... an asset to be capitalized on and mined, given the emic perspective, the unique insight" (Cochran-Smith 
\& Lytle, 2009, p. 101), not readily available through an outside or etic perspective (Cochran-Smith \& Lytle, 1993), one that is essential to the vitality of any comprehensive theory of learning.

No doubt, pursuing such an ambition includes "[t]he potential for silencing" in light "of issues of power and control" on who or what sets the agenda for determining the scope of academic legitimization; one that simply "come[s] with the territory" (Cochran-Smith \& Lytle, 2009, p. 103) of engaging in such interdisciplinary work. More positively put, such cross-disciplinary critical dialogue offers much opportunity for deepening our understanding of the many contexts that impinge on the dynamics of learning in meeting constituent challenges of our current setting.

Discerning the ways in which practitioner researchers could interface with learning theory and instructional design communities of scholars would logically be as diverse as the situations under review warrant. Within such collaborative milieus, the critical factor raised by the practitioner research scholarship remains; the centrality of emic viewpoints in light of more etic, or outsider perspectives of the learning theorists and instructional designers, as discerningly probed in given investigatory processes. Such exploratory research would invariably remain an open issue, one that offers much potential for enhancing the learning process and identifying the knowledge that matters to the students we engage in our classrooms and schools in their interaction with the society and culture that envelops their current and future lives.

In taking a leaf from its roots in experimental learning (Stewart, 1987), the adult education field holds the potential to pioneer such an interdisciplinary dialogue. Such work is especially crucial for a society that has become increasingly defined as postindustrial, pluralistic, global, and knowledge based-an increasingly inclusive learning society, in which how and what we learn plays such a central role in the quality of our personal and public lives in the midst of the many challenges that impinge against them. This essay represents one partial effort toward moving in this direction. The attempt to reconstruct the course under discussion here, as suggested through a more inductive and integrated approach, would provide a practical litmus test, the results of which can only remain speculative at this point. 


\section{References}

Bandura, A. (1994). Self-efficacy. In V. S. Ramachaudran (Ed.), Encyclopedia of human behavior (Vol. 4, pp. 71-81). Academic Press.

Brookfield, S. (1995). Adult learning: An overview. In A. Tuinjman (ed.). International encyclopedia of education. Pergamon Press.

Brookfield, S. (2004). The power of critical theory: Liberating adult learning and teaching. Jossey Bass.

Burke, T. (1994). Dewey's new logic: A reply to Russell. University of Chicago Press.

CASAS. (2008). CASAS competencies: Essential life and work skills for youth and adults. https://www.casas.org/ docs/pagecontents/competencies.pdf?Status=Master

Çeliköz, N., Erişen, Y., \& Şahin, M. (2016). Cognitive learning theories. In Z. Kaya and A. S. Akdemir (Eds.), Learning and teaching: Theories, approaches and models (pp. 31-45). Çözüm.

Cherryholmes, C. C. (1999). Reading pragmatism. Teachers College Press.

Cochran, M. (Ed). (2010). The Cambridge companion to Dewey. Cambridge University Press.

Cochran-Smith, M., \& Lytle, S. L. (1993). Inside/outside: Teacher research and knowledge. Teachers College Press.

Cochran-Smith, M., \& Lytle, S. L. (2009). Inquiry as stance: Practitioner research for the next generation. Teachers College Press.

Cunningham, D. J. (1992). Assessing constructions and assessments: A dialogue. In T. M. Duffy \& D. H. Jonassan, (Ed.), Constructivism and the technology of instruction: A conversation (pp. 35-44). Lawrence Erlbaum.

Demetrion, G. (2000). Practitioner-based inquiry: Theoretical probings. Adult Basic Education, 10(3), 119-146.

Demetrion, G. (2002). Exploring the middle ground: Literacy as growth. Adult Basic Education, 12(1), 34-58.

Demetrion, G. (2005). Conflicting paradigms in adult literacy education: In quest of a U.S. democratic politics of literacy. Lawrence Erlbaum.
Demetrion (G.). (2012). Dewey's logic as a methodological grounding point for practitioner based inquiry. Journal of Research and Practice for Adult Literacy, Secondary, and Basic Education, 1(3), 161-172.

Derry, S. J. (1996). Cognitive schema theory in the constructivist debate. Educational Psychologist, 3(3/4), 163-174.

Dewey, J. (1944). Democracy and education. Free Press. (Original work published 1916).

Dewey, J. (1954). Essays in experiential logic. Dover. (Original work published 1916.

Dewey, J. (1958). Experience and nature. Dover. (Original work published 1929).

Dewey, J. (1991). Logic: The theory of inquiry. Southern Illinois Press (Original work published 1938).

Dewey, J. (1997). Experience and education. Touchtone. (Original work published 1938).

Dirkx, J. M., \& Prenger, S. M. (1997). A guide for planning and implementing instruction for adults: A theme-based approach. John Wiley and Sons.

Duffy, T. M., \& Jonassan, D. H. (Eds.) (1992). Constructivism and the technology of design: A conversation. Lawrence Erlbaum.

Elias, J. L., \& Merriam, S. B. (2005). Philosophical foundations of adult education (3rd ed.) Krieger.

Ertmer, P. A., \& Newby, T. J. (2013), Behaviorism, cognitivism, constructivism: Comparing critical features from an instructional design perspective. Performance Improvement Quarterly, 26(2), 43-71.

Fosnot, C. T. (2005). Constructivism: Theory, perspectives, and practices (2nd ed.). Teachers College Press.

Fosnot, C. T., \& Perry, S. T. (2005). Constructivism: A psychological theory of learning. In C. T. Fosnot (Ed.), Constructivism: Theory, perspectives, and practices (2nd ed., pp. 8-38). Teachers College Press.

Garrison, J. (1997). Dewey and eros: Wisdom and desire in the art of teaching. Teachers College Press. 
Gert, J., Biesta, J., \& Burbles, N. C. (2004). Pragmatism and educational research. Roman and Littlefield.

Henschke, J. A. (2016). A history of andragogy and its documents as they pertain to adult basic and literacy education. PAACE Journal of Lifelong Learning, 25, $1-28$.

Hmelo-Silver, C. E., Duncan, R. G., \& Chinn, C. C. (1997). Scaffolding and achievement in problem-based and inquiry learning: A response to Krishner, Sweller, and Clark (2006). Educational Psychologist, 4(2), 99-107.

Kincheloe, J. L. (2008). Critical constructivism primer. Peter Lang.

Kirschner, P. A. Sweller, J., \& Clark, R. E. (2006). Why minimal guidance does not work: An analysis of the failure of constructivist, discovery, problem-based, experiential, and inquiry-based teaching. Educational Psychologist, 41(2), pp. 75-86.

Knowles, M. Holton, III, E. F., \& Swanson, R. A. (1998). The adult learner: The definitive classic in adult education and human resource development (5th ed.). Gulf.

Mayer, R. E. (1996). Learners as information processors: Legacies and limitations of educational psychology's second metaphor. Educational Psychologist, 3 (3/4), 151-161.

Mayer, R. E. (1999). Designing instruction for constructivist learning. In C. M. Reigeluth (Ed.), Instructional-design theories and models: The new paradigm of instructional theory (pp. 143-159). Lawrence Erlbaum.

Mayer, R. E. (2004). "Should there be a three-strike rule against pure discovery learning?" American Psychologist, 59 (1), 14-19.

Merriam, S. B. (2001). Andragogy and self-directed Learning: Pillars in adult learning theory. New Directions for Adult and Continuing Education, 89, 3-14.
Merriam, S. B. (2017). Adult learning theory: Devolution and future directions. PAACE Journal of Lifelong Learning, 26, 21-37.

Merrill, M. D. (2002). First principles of instruction. Educational Technology Research and Development, 50(3), 43-59.

Merrill, M. D. (1992). Constructivism and instructional design. In T. M. Duffy and D. H. Jonassan (Eds.), Constructivism and the technology of design: A conversation. (pp. 99-114). Lawrence Erlbaum: 1992.

The Partnership for $21^{\text {st }}$ Century Skills. (2009). P21 framework definitions.

Perkins, D. N. (1992). Technology meets constructivism: Do they make a marriage? In T. M. Duffy \& D. H. Jonassan (Eds.), Constructivism and the technology of design: A conversation (pp. 45-55). Lawrence Erlbaum: 1992.

Pimental, S. (2013). College and career readiness standards for adult education. U.S. Department of Education Office of Vocational and Adult Education.

Rorty, R. (1979). Philosophy and the mirror of nature. Princeton University Press.

Stewart, D. W. (1987). Adult learning in America: Eduard Lindeman and his agenda for lifelong learning. Krieger.

Sticht, T. (1997). Functional context education: Making learning relevant. Copian. http://en.copian.ca/library/ research/context/cover.htm.

Tennyson, R. (2005). Learning theories and instructional design: A linking model. In J. M. Spector, C. Ohrazda, A. Van Schaack, \& D.A. Wiley (Eds), Innovations in technology. Essays in honor of M. David Merrill (pp. 219-235). Lawrence Erlbaum. 